change in workload at the perigee, there was a reduction in out of hours calls at the apogee, when the moon's gravitational pull is at its lowest. Further analysis showed that any apparent effect could be explained by the occurrence of more bank holidays on the full moon days in our study period. Though the reduction in workload at the apogee remained significant $(p=0.032)$.
1 Tasso J, Miller E. The effects of the full moon on human behaviour. F Psychol 1976;93:81-3.

2 Payne S, Dearden P, Abercrombie G, Carlson G. Urinary retention and the lunisolar cycle, is it a lunatic phenomenon? $B M F$ 1989;299:1560-2

3 Thakur C, Sharma D. Full moon and crime. $B M \mathcal{F}$ 1984;289:1789-91.

4 Rotton J, Kelly IW. Much ado about the full moon: A metaanalysis of lunar lunacy research. Psychol Bul 1985;97:286-306.

5 Garzino SJ. Lunar effects on mental behaviour: A defence of empirical research. Environment and Behaviour 1982;14(4):395-417.

\title{
Oral contraceptive use and risk of myocardial infarction: an Italian case-control study
}

\author{
Barbara D’Avanzo, Carlo La Vecchia, Eva Negri, Fabio Parazzini, Silvia Franceschi
}

There is consistent evidence that oral contraceptives are associated with increased risk of acute myocardial infarction. There is, moreover, strong synergism between their use and other recognised risk factors for myocardial infarction. In terms of implications for prevention, this has led to the avoidance of oral contraceptives in women at high risk for ischaemic heart disease for other reasons. ${ }^{1}$ These indications for selective prescription have probably been as important for reducing vascular risk as the changes in newer formulations of oral contraceptives. We evaluated the recent impact of oral contraceptives on myocardial infarction in Italy, where its incidence and the pattern of oral contraceptive use ${ }^{2}$ are different compared with northern Europe and America, where most studies have been conducted.

Methods: A case-control study of myocardial infarction was conducted in northern Italy between 1983 and 1992. Its general design has already been described. ${ }^{2}$

Cases were women with diagnosis of a first episode of acute myocardial infarction admitted to the coronary care units of the participating hospitals. A total of 251 cases aged 18 to 54 years (median age 48 ) were included in the study.

Controls were women admitted to the same network of hospitals during the same period, for diseases other than cardiovascular or cerebrovascular and not related to known or potential risk factors for acute myocardial infarction. There were 475 women aged 17 to 54 (median age 48), comparable with cases in terms of age and area of residence. Twenty two per cent of controls were admitted for traumatic conditions, $32 \%$ for other non-traumatic orthopaedic diseases, $18 \%$ for surgical conditions, and $28 \%$ for other miscellaneous diseases, such as acute infections, skin, ear, eye, nose and throat diseases.

Use of oral contraception was investigated through questions about the duration of each episode of use in months, the age at first and at last use, and, whenever possible, the brand.

Standard methods of analysis of case-control study, based on unconditional logistic regression, were used to derive odds ratios (OR), and the corresponding $95 \%$ confidence intervals (CI). ${ }^{3}$

Results: A total of $2 \cdot 8 \%$ of cases versus $1 \cdot 3 \%$ of controls were current users of oral contraceptives and $17 \cdot 1 \%$ versus $9 \cdot 7 \%$ were past users. The multivariate OR were 2.0 for current and 1.8 for past users. The risk of acute myocardial infarction decreased with increasing time since last use, although it was still high, but not significantly, two or more years since last use (Table).

With reference to the combined effect of oral contraceptives and major covariates, compared with non-smokers who were non-users of oral contraceptives, the $\mathrm{OR}$ of acute myocardial infarction for smokers who were oral contraceptive users was $6 \cdot 1(95 \% \mathrm{CI} 3 \cdot 4,11 \cdot 0)$. Compared with normotensive women who had never used oral contraceptives, the OR was 28.4 (95\% CI $6.7,120 \cdot 1)$ for hypertensive women who had ever used oral contraceptives (17 cases and 2 controls). In hyperlipidaemic women who had ever used oral contraceptives the OR was $4.4(95 \% \mathrm{CI} 1.3,15 \cdot 2)$ compared to never users who were normolipidaemic.

Discussion: Some studies found an increased risk of acute myocardial infarction limited to current oral contraceptive users, and a decreased risk with time since stopping oral contraceptive use, with a sharp reduction in the risk after stopping. ${ }^{4}$ In other investigations there was some persistence of risk also after stopping. ${ }^{5}$

The persistence, in this study, of some increased risk in women who had stopped using oral contraceptives supports some effect of these drugs on atherogenesis, which would be consistent with their action on the lipid profile.

This study confirms the substantially raised risk in women exposed to both oral contraceptive use and smoking, and suggests an action of both risk factors on similar aspects of the patho- 
Distribution of 251 cases of acute myocardial infarction ( $A M I)$ and 475 controls and odds ratios (with $95 \%$ confidence intervals, $C I$ ) according to oral contraceptive (OC) use. Italy, 1983-92.

\begin{tabular}{|c|c|c|c|c|}
\hline & \multirow{2}{*}{$\frac{A M I}{\text { No }(\%)}$} & \multirow{2}{*}{$\frac{\text { Controls }}{\text { No }(\%)}$} & \multicolumn{2}{|c|}{ Odds ratios $*(95 \% C I)$} \\
\hline & & & $R R 1$ & $R R 2$ \\
\hline $\begin{array}{l}\text { OC use: } \\
\text { Never users } \\
\text { Ever users }\end{array}$ & $\begin{array}{r}201(80 \cdot 1) \\
50(19 \cdot 9)\end{array}$ & $\begin{array}{r}423(89 \cdot 1) \\
52(10 \cdot 9)\end{array}$ & $\begin{array}{l}1+ \\
2 \cdot 2(1 \cdot 4,3 \cdot 4)\end{array}$ & $\begin{array}{l}1 \dagger \\
1.7(1 \cdot 1,3 \cdot 1)\end{array}$ \\
\hline $\begin{array}{l}\text { Current users } \\
\text { Past users }\end{array}$ & $\begin{array}{c}7(2 \cdot 8) \\
43(17 \cdot 1)\end{array}$ & $\begin{array}{r}6(1 \cdot 3) \\
46(9 \cdot 7)\end{array}$ & $\begin{array}{l}2.9(0.9,9 \cdot 3) \\
2 \cdot 1(1 \cdot 3,3 \cdot 4)\end{array}$ & $\begin{array}{l}2 \cdot 0(0 \cdot 6,6 \cdot 7) \\
1 \cdot 8(1 \cdot 0,3 \cdot 2)\end{array}$ \\
\hline $\begin{array}{l}\text { Duration of use: } \\
\leqslant 2 \text { years } \\
>2 \text { years }\end{array}$ & $\begin{array}{l}23(9 \cdot 2) \\
27(10 \cdot 8)\end{array}$ & $\begin{array}{l}25(5 \cdot 3) \\
27(5 \cdot 7)\end{array}$ & $\begin{array}{l}2 \cdot 1(1 \cdot 1,3 \cdot 9) \\
2 \cdot 3(1 \cdot 3,4 \cdot 0)\end{array}$ & $\begin{array}{l}2 \cdot 1(1.0,4 \cdot 4) \\
1.5(0.7,2 \cdot 9)\end{array}$ \\
\hline $\begin{array}{l}\text { Time since last use: } \\
\leqslant 2 \text { years } \\
>2 \text { years }\end{array}$ & $\begin{array}{c}8(3 \cdot 2) \\
35(13 \cdot 1)\end{array}$ & $\begin{array}{r}6(1 \cdot 3) \\
40(7 \cdot 4)\end{array}$ & $\begin{array}{l}3.5(1.2,10.5) \\
1.9(1.2,3.2)\end{array}$ & $\begin{array}{l}2.8(0.8,9.3) \\
1.7(0.9,3.0)\end{array}$ \\
\hline
\end{tabular}

* Estimates from multiple logistic regression equations including, for RR1: age in quinquennia and area of residence; for RR2: age, area of residence plus smoking habits (never smoker/exsmoker/current smoker of $<20$ cigarettes/day, $\geqslant 20$ cigarettes/day), body mass index, history of angina, diabetes, hypertension, and hyperlipidaemia.

t Reference category. genic process. An additive effect was observed for hyperlipidaemia, whereas the greatly increased risk of women reporting both oral contraceptive use and hypertension was more consistent with a multiplicative effect on the OR.
From a public health viewpoint, only about $1 \%$ of events of acute myocardial infarction in this population is attributable to oral contraceptive use, in strong contrast with the approximate $50 \%$ attributable to smoking among Italian women. ${ }^{2}$ The association between oral contraceptive use and acute myocardial infarction is now of a modest importance on a public health level in this population.

This work was conducted within the framework of the CNR (Italian National Research Council) Applied Project "Prevention and Control of Disease Factors" (Contract

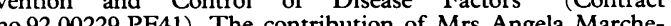
no 92.00229.PF41). The contribution of Mrs Angela Marchegiano Borgomainerio is gratefully acknowledged. The authors

thank Mrs Judy Baggott, Mrs Ivana Garimoldi, and the GA

1 Thorogood M. Oral contraceptives and cardiovascular disease: An epidemiologic overview. Pharmacoepidemiol Drug Saf 1993;2:3-16.

2 La Vecchia C, Franceschi S, Decarli A, Pampallona S, Tognoni G. Risk factors for myocardial infartion in young women. Am f Epidemiol 1987;125:832-43.

3 Breslow NE, Day NE. Statistical methods in cancer research. Vol 1. The analysis of case-control studies. Lyon: IARC Science Publications 1980;32.

4 Stampfer MJ, Willett WC, Colditz GA, Speizer FE, Hennekens $\mathrm{CH}$. A prospective study of past use of oral contraceptive agents and risk of cardiovascular diseases. contraceptive agents and risk

5 Royal College of General Practitioners. Further analysis of mortality in oral contraceptive users. Lancet 1981;i:541-6.

\title{
The "healthy passive smoker": relationship between bronchial hyper-reactivity in school children and maternal smoking
}

\author{
R Meinert, Th Frischer, J Kuehr
}

The term 'healthy smoker effect' describes a primary process of self selection by which only healthy subjects tend to start smoking, and a secondary process of disease related attrition by which subjects with a lung disorder are likely to stop smoking. We present data from a cross sectional study on the association between maternal smoking and bronchial hyper-reactivity (BHR) in 14018 year old school children, in whom the phenomenon of "healthy passive smokers" was observed. ${ }^{1}$ Information on the children's asthma status and maternal smoking was gathered via parental questionnaires. Maternal smoking ("yes/no") was recorded for the time before pregnancy, during pregnancy, in the child's 1st year of life and the child's 8th year of life. BHR was assessed by a free running test and defined as a fall in peak expiratory flow rate $\geqslant 15 \%$ after exercise.

Results: Ninety two children $(6 \cdot 6 \%)$ had BHR. Of 162 asthmatics, $25(15.4 \%)$ had BHR. There was a positive association between BHR and maternal smoking before pregnancy, during pregnancy, and in the children's 1st year of life, but not for the children's 8th year of life (figure). In asthmatics these associations were more pronounced. A negative relationship was found in the children's 8th year of life. After pregnancy, $15 \cdot 2 \%$ (asthmatics: $20 \%$ ) of mothers of children with BHR compared with $8 \cdot 6 \%$ (asthmatics: $8 \cdot 0 \%$ ) of mothers of children without BHR began smoking. Between the child's 1st and 8th year, $7 \cdot 6 \%$ (asthmatics: $0 \%$ ) of mothers of children with BHR compared with $11 \cdot 3 \%$ (asthmatics: $11 \cdot 7 \%$ ) of mothers of children without BHR began smoking, while $7 \cdot 6 \%$ (asthmatics: $16.0 \%$ ) of mothers of responsive children stopped smoking compared with $3.4 \%$ (asthmatics: $2.9 \%$ ) of those with unaffected children. This association between BHR and changes in maternal smoking habits was significant ( $p=0.021$, Fisher's exact test) in asthmatics but not in the whole sample $(p=0 \cdot 11)$. Discussion: Our data suggest that mothers of children with BHR, especially mothers of asthmatic children, seemed less likely to take up smoking. Furthermore, the occurrence of BHR obviously stimulated mothers to quit smoking. Hence, the use of the term "healthy passive smoker" seems to be justified, although possible biases exist. We can only speculate about the true inter-relation between exposure and disease, since we do not know when a child developed BHR for the first time. Information on maternal smoking status was gathered retrospectively for an eight year period, which could cause reporting bias. Nevertheless, we think the overall impression of changes in maternal smoking habits with regard to the time course and the children's 